\title{
The C Terminus of the Human Nicotinic $\alpha 4 \beta 2$ Receptor Forms a Binding Site Required for Potentiation by an Estrogenic Steroid
}

\author{
Ken Paradiso, Jessie Zhang, and Joe Henry Steinbach \\ Department of Anesthesiology, Washington University School of Medicine, St. Louis, Missouri 63110
}

In addition to actions mediated by changes in gene expression, steroids can directly modulate several transmitter-gated and voltage-gated ion channels. Despite numerous studies showing that steroids enhance or reduce ion channel activity, the site(s) that mediates steroid recognition is not known. To identify the regions in which steroids bind and affect ion channel activity, we have taken advantage of the observation that human $\alpha 4 \beta 2$ neuronal nicotinic receptors are potentiated by an estrogen steroid, $17 \beta$-estradiol, whereas a rat $\alpha 4 \beta 2$ receptor is not. Mutations indicate that a sequence (AGMI) at the end of the $C$ terminus of the human $\alpha 4$ subunit forms a binding site required for $17 \beta$-estradiol potentiation. In contrast, ethynyl $\beta$-estradiol (an oral contraceptive) potentiates both human and rat $\alpha 4 \beta 2$ receptors. A single tryptophan in the $\mathrm{C}$ terminus of both the rat and the human $\alpha 4$ subunit is sufficient for potentiation by ethynyl $\beta$-estradiol, probably through a $\pi-\pi$ interaction. Mutation of this tryptophan eliminates the ability of ethynyl $\beta$-estradiol to potentiate rat receptors. However, in human receptors it was necessary to mutate both the AGMI sequence and the tryptophan to eliminate potentiation by ethynyl $\beta$-estradiol. The findings that $\beta$-estradiol requires the AGMI sequence but that a single $\mathrm{C}$-terminal tryptophan is sufficient for potentiation by ethynyl $\beta$-estradiol indicate that the $\mathrm{C}$ terminus forms a binding site for these steroids. The binding site(s) for block appears to differ from those involved in potentiation because the C-terminal sequence does not affect block by steroids such as progesterone, and progesterone does not competitively inhibit potentiation.

Key words: nicotinic receptors; estrogen; steroids; potentiation; binding site; ligand-gated ion channel
The physiological actions of steroids are typically associated with initiation of gene transcription after binding to cytosolic steroid receptors. However, steroids can also have immediate effects that require a more direct mechanism of action, including effects on neuronal excitability by "neuroactive" steroids (Paul and Purdy, 1992; Rupprecht and Holsboer, 1999). Rapid modulation of neuronal excitability by neuroactive steroids is particularly interesting because some of these steroids are produced in the brain (socalled neurosteroids), either de novo from cholesterol or by enzyme-mediated modification of another steroid (Robel and Baulieu, 1995). Localized production and the ability to alter ion channel kinetics suggest the possibility of selective actions of neurosteroids in specific brain regions. For example, aromatase $\mathrm{P} 450$, the enzyme that produces estradiol, is found both presynaptically and postsynaptically (Balthazart and Ball, 1998), and RNA encoding aromatase P450 is found in the hippocampus and the temporal and frontal neocortex of the adult human brain (Stoffel-Wagner et al., 1999). Estrogen has been shown to influence various ion channels (McEwen and Alves, 1999; Valverde et al., 1999); therefore, local estrogen synthesis could affect activity at both sides of the synapse.

Although it is thought that steroids can bind to ion channels, efforts to locate a specific binding site have been unsuccessful.

Received May 9, 2001; revised June 21, 2001; accepted June 26, 2001.

This work was supported by National Institutes of Health Grants P01 GM47969 and R01 NS22356 (J.H.S.). J.H.S. is the Russell and Mary Shelden Professor of Anesthesiology. We thank Dr. Douglas F. Covey for providing steroids and for advice on their use and effects, G. Akk for comments during the studies, and J. Bracamontes for advice on molecular biology.

Correspondence should be addressed to Dr. Kenneth Paradiso, Department of Anesthesiology, Washington University School of Medicine, 660 South Euclid Avenue, St. Louis, MO 63110. E-mail: paradiso@morpheus.wustl.edu.

Copyright (C) 2001 Society for Neuroscience $\quad 0270-6474 / 01 / 216561-08 \$ 15.00 / 0$
Here, we show that $17 \beta$-estradiol, an estrogenic steroid, directly potentiates responses from the human $\alpha 4 \beta 2$ neuronal nicotinic receptor, and that the $\mathrm{C}$ terminus of the $\alpha 4$ subunit is likely to form the binding site necessary for potentiation.

The $\alpha 4 \beta 2$ receptor represents a major part of the total brain content of nicotinic receptors (Flores et al., 1992), accounts for $80-90 \%$ of the high-affinity nicotine binding sites in the brain (Marubio et al., 1999), and is diminished in the brains of patients with Alzheimer's disease (Sugaya et al., 1990; Wevers et al., 1999). Nicotinic receptors are involved in a variety of neurological disorders (Kuryatov et al., 1997; Lindstrom, 1997; Paterson and Nordberg, 2000), and increasing evidence suggests that presynaptic nicotinic receptors have an important physiological role in modulating the release of many neurotransmitters (McGehee et al., 1995; Gray et al., 1996; Coggan et al., 1997; Wonnacott, 1997; Paterson and Nordberg, 2000). Therefore, modulation of nicotinic receptors by estrogen or other compounds is likely to influence synaptic signaling in several pathways.

We previously established that $17 \beta$-estradiol, $\beta \mathrm{E} 2$, inhibits a receptor formed from a rat $\alpha 4 \beta 2$ neuronal nicotinic receptor (Paradiso et al., 2000), in contrast to the ability of $\beta \mathrm{E} 2$ to potentiate human $\alpha 4 \beta 2$ receptors (Buisson et al., 1998). We explored this apparent contradiction to determine the difference between block and potentiation and to identify the portions of the protein that are responsible for potentiation.

\section{MATERIALS AND METHODS}

Synthesis and expression of cDNA encoding chimeric and mutated subunits. cDNA constructs for human $\alpha 4$ (Kuryatov et al., 1997) and $\beta 2$ (Anand and Lindstrom, 1990) subunits were kindly provided by Dr. Jon Lindstrom (University of Pennsylvania, Philadelphia, PA) in pSP64 and were transferred to pcDNA3 (Invitrogen, Carlsbad, CA) for use. Rat $\alpha 4$ and $\beta 2$ subunits were kindly provided by Dr. J. Patrick (Baylor College of 
Medicine, Houston, TX) (Sabey et al., 1999). Because of the high homology between the rat and human subunits, identical restriction sites could be found for the production of chimeras. Three sets of chimeric $\alpha 4$ subunits were made; for each set, one chimera was made with the rat sequence from the $\mathrm{N}$ terminus to the chimeric join, whereas the other chimera was made with the human sequence at the $\mathrm{N}$ terminus. The chimera pairs were made at the following amino acid residues (numbered for the mature protein): X1, 131/132 (AatII); X2, 296/297 (Alw44I); and X3 , rat 268/human 268 or human 267/rat 269 (ScaI). The human $\alpha 4$ subunit was excised with HindIII and BamHI, whereas rat $\alpha 4$ was excised with HindIII and $X b a \mathrm{I}$; next, the subunits were digested separately with the specific restriction endonuclease, and fragments were purified by gel electrophoresis. pcDNA3 was digested with HindIII and XbaI or Bam HI (as appropriate), and the opened vector was purified. The two appropriate subunit fragments from the subunits were then mixed with the opened pcDNA3 and ligated.

All point mutations were generated using the QuikChange sitedirected mutagenesis kit (Stratagene, La Jolla, CA). For reasons that are not clear to us, it was more efficient to mutate the rat $\alpha 4$ construct in pcDNA3. Accordingly, many of the mutations in the C-terminal tail region were generated this way, after it had been shown that other regions of the subunit did not affect potentiation (see Results). All chimeras and point mutations were sequenced through the entire translated region to confirm that the appropriate changes had been introduced, and that no additional mutations were generated in the sequence.

Nicotinic receptors were expressed in Xenopus oocytes by injecting the nuclei of defolliculated oocytes using the blind method described by Colman (1984). cDNA constructs encoding an $\alpha 4$ and a $\beta 2$ subunit at a concentration of $200 \mathrm{ng} / \mu \mathrm{l}$, mixed at a 1:1 ratio, were used for all experiments. Nuclei were microinjected with $13.6 \mathrm{nl}$ of cDNA-containing solution into the nucleus of the oocyte. Oocytes were incubated at $18^{\circ} \mathrm{C}$ for 2-4 d before biophysical recordings.

Two-electrode voltage-clamp recordings. A two-electrode voltage clamp (Warner Instruments, Hamden, CT) was used to record currents from oocytes. Both voltage and current electrodes had resistances of $\sim 1 \mathrm{M} \Omega$ and were filled with $3 \mathrm{M} \mathrm{KCl}$; silver chloride pellets were used for the bath and virtual ground. The oocyte recording chamber had a volume of $\sim 0.1 \mathrm{ml}$ and was continuously perfused with solution (either bath or test) at a rate of $\sim 7 \mathrm{ml} / \mathrm{min}$. Solutions were switched by hand, using Teflon rotary valves (Rheodyne, Rohnert Park, CA). Because of the lipophilic nature of the steroids used in our experiments, glass syringes, Teflon tubing, and Teflon valves were used in the perfusion apparatus.

To prevent the activation of $\mathrm{Ca}^{2+}$-activated chloride currents found in oocytes, $\mathrm{Ca}^{2+}$ was replaced with $\mathrm{Ba}^{2+}$ (Briggs et al., 1995). The following external solution was therefore used (in $\mathrm{mm}$ ): $96 \mathrm{NaCl}, 2 \mathrm{KCl}, 1.8$ $\mathrm{BaCl}_{2}, 1 \mathrm{MgCl}_{2}$, and $10 \mathrm{HEPES}, \mathrm{pH}$ 7.3. Acetylcholine (ACh) chloride (Sigma, St. Louis, MO) was prepared as a $1 \mathrm{M}$ stock solution in ion exchange-purified distilled water and stored in aliquots at $-20^{\circ} \mathrm{C}$. Steroids were purchased from Sigma or Steraloids (Newport, RI) or were synthesized by the laboratory of Dr. Doug Covey (Washington University, St. Louis, MO). Stock solutions were prepared as $10 \mathrm{~mm}$ steroid dissolved in DMSO and stored at room temperature in the dark. Working solutions were made up on the day of the experiment in external solution. The standard test concentration of $15 \mu \mathrm{M}$ steroid resulted in a solution containing $0.15 \%$ DMSO, but control experiments with DMSO alone indicated that this concentration had no effect on ACh responses (data not shown) (Paradiso et al., 2000).

Data were filtered at $20 \mathrm{~Hz}$ using an eight-pole Bessel filter (Frequency Devices, Haverhill, MA), digitized at $50 \mathrm{~Hz}$ using a Digidata 1200 (Axon Instruments, Union City, CA), and analyzed with a PC clone computer using pClamp6 and pClamp8 software (Axon Instruments). The response was measured as the difference between the average response in a 1-2 sec window including the peak of the response and the average baseline current in an $\sim 2 \mathrm{sec}$ window before the onset of response. The effect of steroids was determined by taking the ratio of the response in the presence of steroid to the average of control responses measured before and after the test application. One complicating factor was that the amount of potentiation produced by our standard test applications varied between batches of oocytes, with mean values from 1.6-fold to 5.9 -fold increases in response in the presence of $\beta \mathrm{E} 2$ on different batches. A single-factor ANOVA test gave a $p$ value of 0.001 that the difference between batches was random. We do not have an explanation for the variability. To compensate for the variability, in some cases (as noted in Fig. 5) we compared the amount of potentiation within a given batch of oocytes, in addition to tests on pooled data.

\section{A Human $\alpha 4 \beta 2$}

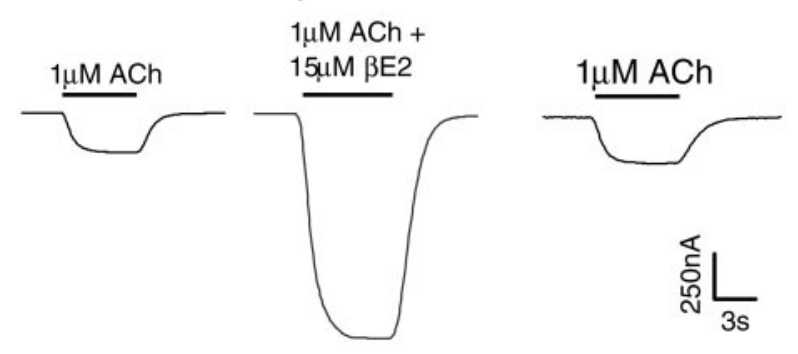

B Rat $\alpha 4 \beta 2$

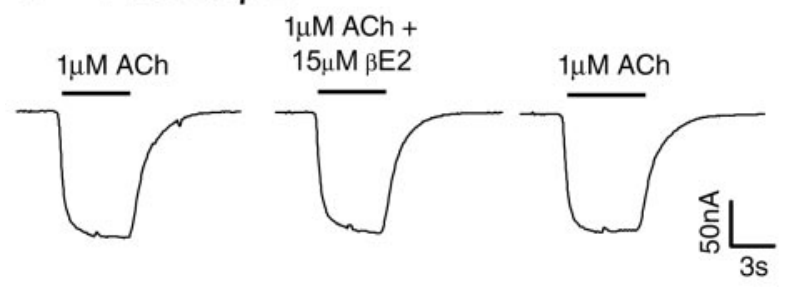

Figure 1. $\quad \beta \mathrm{E} 2$ potentiates responses from human $\alpha 4 \beta 2$ nicotinic receptors expressed in Xenopus oocytes but not responses from rat $\alpha 4 \beta 2$ receptors. $A$, The responses of an oocyte injected with human wild-type $\alpha 4$ plus $\beta 2$ subunit cDNA to an application of $1 \mu \mathrm{M}$ ACh and then to $1 \mu \mathrm{M}$ ACh coapplied with $15 \mu \mathrm{M} \beta \mathrm{E} 2$ and finally the recovery response to $1 \mu \mathrm{M}$ ACh alone ( $\sim 2$ min after the co-application). Preapplication of $\beta E 2$ did not increase the amount of potentiation (data not shown). $B$, Similar responses of an oocyte injected with rat wild-type $\alpha 4$ plus $\beta 2$ subunit cDNA.

Data analysis and statistical tests were done using Excel (Microsoft, Seattle, WA) and Sigma Plot (SPSS, Chicago, IL).

\section{RESULTS}

\section{Potentiation of human $\alpha \mathbf{4} \beta 2$ receptors}

Coapplication of $15 \mu \mathrm{M} \beta \mathrm{E} 2$ with $1 \mu \mathrm{M}$ ACh potentiated (3.9fold $\pm 1.2 \mathrm{SD} ; n=84$ ) the response of human $\alpha 4 \beta 2$ nicotinic receptors expressed in Xenopus oocytes (Fig. 1 $A$ ) but did not potentiate responses from a rat $\alpha 4 \beta 2$ receptor (Fig. $1 B)(1.02 \pm$ $0.14 \mathrm{SD} ; n=36)$. Potentiation was assessed from the peak response to coapplication of $\mathrm{ACh}$ and steroid, compared with the peak response to $\mathrm{ACh}$ alone. It should be noted that two forms of the rat $\alpha 4$ subunit are expressed in the rat brain, $\alpha 4-1$ and $\alpha 4-2$ (Deneris et al., 1988). The forms differ only at the extreme C terminus, and the mRNAs for the two forms are present at approximately equal levels in rat brain. For simplicity, we refer to rat $\alpha 4-1$ subunits as rat $\alpha 4$ in this paper.

As seen for other studies of potentiation of ligand-gated ion channels, the amount of potentiation of the human $\alpha 4 \beta 2$ receptor is greater at lower agonist concentrations (Fig. 2A,B). Accordingly, the experiments reported below were performed using $1 \mu \mathrm{M}$ ACh because this represents a submaximal agonist concentration (Fig. $2 A$ ). The lack of potentiation for the rat $\alpha 4 \beta 2$ receptor did not result from major differences in activation of rat or human receptors, because $1 \mu \mathrm{M} \mathrm{ACh}$ is a low concentration for both types of receptors (Fig. $2 A$ ). The concentration of $15 \mu \mathrm{M} \beta \mathrm{E} 2$ used in Figure $1 A$ provides close to maximal potentiation (Fig. 2C).

\section{Potentiation and inhibition by steroids are separate and independent processes}

In addition to causing potentiation, steroids have been shown to inhibit the responses of neuronal nicotinic $\alpha 4 \beta 2$ receptors (Ber- 

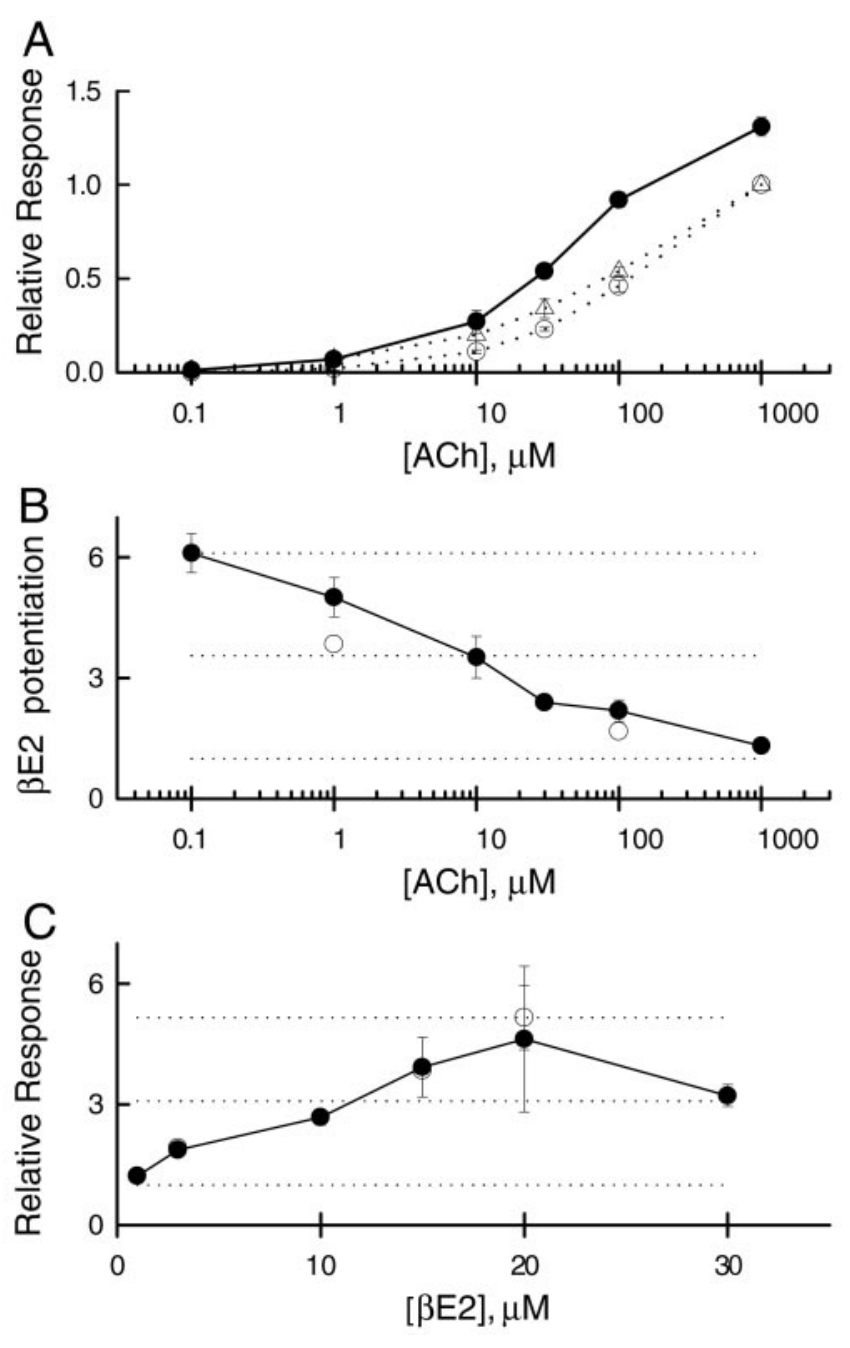

Figure 2. Concentration-response data for $\mathrm{ACh}$ and $\beta \mathrm{E} 2 . A$, The relative response to various concentrations of $\mathrm{ACh}$, normalized to the response to $1 \mathrm{mM}$, in the absence of $\beta \mathrm{E} 2$. Human $\alpha 4 \beta 2$, open circles; rat $\alpha 4 \beta 2$, open triangles. Coapplication of $15 \mu \mathrm{M} \beta \mathrm{E} 2$ enhances the response from the human receptor ( filled circles). Lines simply connect the points, whereas points show mean \pm 1 SEM for three to six oocytes (derived from two batches). $B$, Potentiation of the human wild-type receptor response produced by coapplication of $15 \mu \mathrm{M} \beta \mathrm{E} 2$ plus various concentrations of $\mathrm{ACh}$ indicates that potentiation is greater at lower concentrations of $\mathrm{ACh}$. The dotted lines show values of 1 (no potentiation), half the observed maximal potentiation, and maximal observed potentiation. Filled circles show data derived from oocytes tested at multiple concentrations (3 oocytes at each point), whereas open circles show pooled data from all oocytes tested (36 oocytes at $100 \mu \mathrm{M} \mathrm{ACh}$ and 84 oocytes at $1 \mu \mathrm{M} \mathrm{ACh}$ ). $C$, The potentiation produced by various concentrations of $\beta \mathrm{E} 2$ coapplied with $1 \mu \mathrm{M} \mathrm{ACh}$ indicate an $\mathrm{EC}_{50}$ value of $\sim 10 \mu \mathrm{M}$ for $\beta \mathrm{E} 2$. The apparent decrease between $20 \mu \mathrm{M}$ and $30 \mu \mathrm{M} \beta \mathrm{E} 2$ is not statistically significant, although it could reflect mixed potentiation and block by $\beta \mathrm{E} 2$ at high concentrations. Filled circles show data derived from oocytes tested at multiple concentrations ( 3 oocytes at $3 \mu \mathrm{M}, 2$ oocytes at $20 \mu \mathrm{M}$, and 6 oocytes at other concentrations), whereas open circles show pooled data from all oocytes tested ( 13 oocytes at $3 \mu \mathrm{M}, 84$ oocytes at $15 \mu \mathrm{M}$, and 4 oocytes at $20 \mu \mathrm{M})$. The two symbols overlap at 3 and $15 \mu \mathrm{M} \beta \mathrm{E} 2$.

trand et al., 1991; Valera et al., 1992; Sabey et al., 1999; Paradiso et al., 2000). Indeed, human $\alpha 4 \beta 2$ receptors expressed in oocytes are inhibited by some steroids (Fig. 3, Table 1). Accordingly, we examined the question of whether potentiation and inhibition might be related processes; for example, inhibition could result from the action of an "inverse agonist" that bound to the same

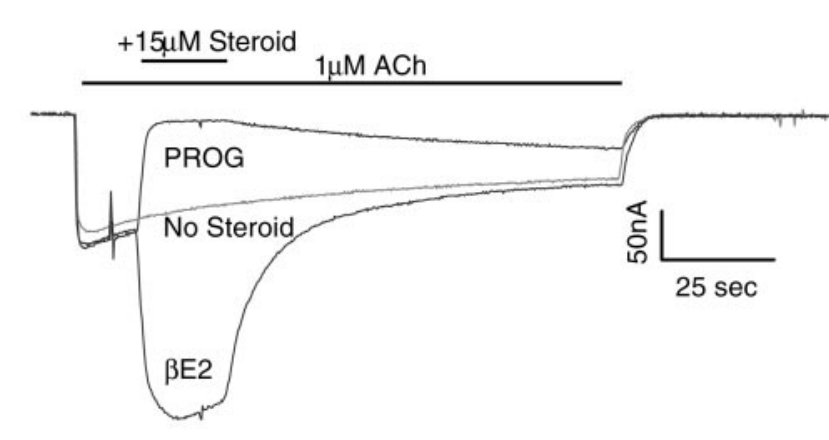

Figure 3. The onset and offset of potentiation are rapid. The response of a single oocyte to a long application of $1 \mu \mathrm{M}$ ACh shows a slow decline reflecting desensitization (light trace). When a long application is made but the solution is switched from $1 \mu \mathrm{M}$ ACh to $1 \mu \mathrm{M}$ ACh plus $15 \mu \mathrm{M} \beta \mathrm{E} 2$ during the application, the response is rapidly potentiated, and on return to $1 \mu \mathrm{M}$ ACh alone rapidly returns to the same level as the response to 1 $\mu \mathrm{M}$ ACh alone. In contrast, when the solution is switched to one containing $1 \mu \mathrm{M}$ ACh plus $15 \mu \mathrm{M}$ PROG, the response is rapidly blocked but recovers extremely slowly on return to $1 \mu \mathrm{M}$ ACh alone. The responses were taken sequentially, with ACh alone first, followed by ACh plus $\beta E 2$ and then ACh plus PROG. The holding current has been subtracted but the traces have not been normalized. There apparently was a small increase in response amplitude between the initial control application and the test applications. Bars indicate onset and duration of drug application.

site as potentiating steroids. Our observations indicate that potentiation is distinct from inhibition.

We used progesterone (PROG) as an example of an inhibitory steroid. One difference between inhibition and potentiation is that inhibition reversed relatively slowly (Fig. 3) (Paradiso et al., 2000). We also found that the requirements for the steroid structures that produce potentiation (discussed in next section) differ from those that produce inhibition (Paradiso et al., 2000). Finally, pharmacological experiments indicate that inhibition and potentiation are independent processes. We examined this by coapplying an inhibiting steroid (PROG) with a potentiating steroid $(\beta E 2)$ and determining whether inhibition was reduced by potentiation (Table 1). If the presence of the potentiating steroid reduced inhibition, this would suggest that the two mechanisms shared some parts of a pathway (perhaps as early as a binding site). For the competition experiments, $3 \mu \mathrm{M}$ or $15 \mu \mathrm{M}$ PROG was preapplied for $20 \mathrm{sec}$ to ensure that the inhibiting steroid had ample time to interact with its binding site.

For either concentration of PROG there was no significant difference between the amounts of block among the different $\beta \mathrm{E} 2$ concentrations (Table 1) ( $p>0.06$ for all comparisons). In an additional experiment, $3 \mu \mathrm{M}$ PROG and $15 \mu \mathrm{M} \beta \mathrm{E} 2$ were preapplied together for $20 \mathrm{sec}$ to allow interactions between steroids to reach equilibrium. The response was then tested with $1 \mu \mathrm{M} \mathrm{ACh}$ plus $3 \mu \mathrm{M}$ PROG and $15 \mu \mathrm{M} \beta \mathrm{E} 2$, and the test response was reduced to $0.22 \pm 0.06$ (four cells). The reduction did not differ from that seen when only $3 \mu \mathrm{M}$ PROG was preapplied (Table 1). Accordingly, the actions of steroids to potentiate and to block responses of the human $\alpha 4 \beta 2$ receptor do not show competition and so are unlikely to involve binding to the same or overlapping portions of the receptor.

However, block is a confounding factor in the analysis of potentiation. In particular, the presence of block might be significant in comparisons among steroids of differing structure because it is likely that steroids that potentiate can also block to some extent. Hence, stronger block might be observed as weaker potentiation, or vice versa. 
Table 1. Progesterone block of the human $\alpha 4 \beta 2$ receptor in the absence and presence of $\beta$-estradiol indicates a lack of competition

\begin{tabular}{llll} 
& No $\beta$-estradiol & $+3 \mu \mathrm{M} \beta \mathrm{E} 2$ & $+15 \mu \mathrm{M} \beta \mathrm{E} 2$ \\
\hline $3 \mu \mathrm{M}$ PROG & $0.37 \pm 0.13(n=7)$ & $0.22 \pm 0.05(n=4)$ & $0.25 \pm 0.03(n=4)$ \\
$15 \mu \mathrm{M}$ PROG & $0.10 \pm 0.04(n=4)$ & $0.08 \pm 0.04(n=7)$ & $0.05 \pm 0.01(n=3)$
\end{tabular}

$\beta E 2$ refers to $17 \beta$-estradiol. PROG ( 3 or $15 \mu \mathrm{M}$ ) was pre-applied for $20 \mathrm{sec}$ before a test pulse containing $1 \mu \mathrm{M}$ ACh plus the concentration of PROG that was pre-applied plus 0,3 , or $15 \mu \mathrm{M} \beta \mathrm{E} 2$. The table shows the relative response in the presence of PROG ( 3 or $15 \mu \mathrm{M}$ ) to the response in the absence of PROG: the first data column is normalized to $1 \mu \mathrm{M}$ ACh (no $\beta \mathrm{E} 2$ ); the second column is normalized to $1 \mu \mathrm{M}$ ACh plus $3 \mu \mathrm{M} \beta \mathrm{E} 2$; and the third column is normalized to $1 \mu \mathrm{M}$ ACh plus $15 \mu \mathrm{M} \beta \mathrm{E} 2$. The $\mathrm{SD}$ follows and the $n$ value is shown in parentheses.

\section{Features of steroid structure important for potentiation}

We first examined the ability of several steroids and some estrogen receptor agonists to potentiate human $\alpha 4 \beta 2$ nicotinic receptors. Some important basic features of steroid structure are shown in Figure $4 A$, including the ring nomenclature, with the A ring highlighted to indicate its importance, and arrows marking the critical carbon 3 and 17 positions. The standard concentration of steroid adopted was $15 \mu \mathrm{M}$, because this concentration produced close to maximal potentiation for $\beta \mathrm{E} 2$ (Fig. $2 C$ ). In addition, these steroids can precipitate out of solution at concentrations of $>20 \mu \mathrm{M}$; thus $15 \mu \mathrm{M}$ represents a reasonable test concentration while still being low enough to minimize issues of steroid solubility.

The mirror image of $\beta \mathrm{E} 2$ (ent- $\beta \mathrm{E} 2$ ) (Fig. $4 A$ ) was ineffective at potentiating; therefore, the steroid interacts with a site that recognizes the stereochemistry of the steroid. Enantioselectivity indicates that $\beta \mathrm{E} 2$ does not act by some bulk effect on the membrane, because the physical properties of enantiomers are identical, suggesting that $\beta \mathrm{E} 2$ is binding to a protein.

Strong potentiation required an unsaturated $\mathrm{A}$ ring and a free hydroxyl group at the 3 and 17 position (Fig. $4 A$ ). An A ringsaturated analog of $\beta \mathrm{E} 2(3 \beta 17 \beta \mathrm{ED})$ and the 3 -methyl ether of $\beta \mathrm{E} 2$ (3Me $\beta \mathrm{E} 2)$ were ineffective at potentiating (Fig. $4 B$ ), as was the 3-methyl ether of $17 \alpha$-vinyl $\beta$ E2 (mestranol). Removal of the 17-hydroxyl group (E0) or replacement with a keto group (E1) produced ineffective compounds, as did the addition of a third hydroxyl group (E3) at carbon 16 (Fig. 4C). Because our experiments do not separate affinity from efficacy, it is possible that some of the structural requirements for potentiation reflect occupancy, whereas others reflect the ability to produce potentiation.

Consistent with the structural features required for potentiation discussed above, the steroids shown in Figure $4 D$ potentiated responses. A diastereoisomer of $\beta \mathrm{E} 2,17 \alpha$-estradiol $(\alpha \mathrm{E} 2)$ potentiated responses almost as well as $\beta \mathrm{E} 2$, indicating that the presence of the 17-hydroxyl group is critical, whereas the stereochemistry is less important (Fig. 4D). Two other steroids were at least as effective at potentiation as $\beta \mathrm{E} 2$ : $17 \alpha$-vinyl $\beta \mathrm{E} 2$ (ethynyl $\beta \mathrm{E} 2$ ) and a steroid with a partially unsaturated $\mathrm{B}$ ring $(\Delta 7 \beta \mathrm{E} 2)$. These three steroids (Fig. $4 D$ ) contain the same critical structural features of $\beta E 2$ : an unsaturated A ring and free hydroxyl groups at the 3 and 17 position.

We believe that the steroids directly interact with the nicotinic receptor and are not acting through estrogen receptors. Although the human $\alpha 4 \beta 2$ nicotinic receptor and the nuclear estrogen receptors share requirements for steroid structure (Anstead et al., 1997; Kuiper et al., 1997; Wiese et al., 1997), there are some clear differences between agonists for the nicotinic receptor and the estrogen receptor. Specifically, for human estrogen receptors, $\alpha \mathrm{E} 2$ is much worse at binding or activating than is $\beta \mathrm{E} 2$ and $\mathrm{E} 0$,
A Steroid structure and demonstration of enantioselectivity

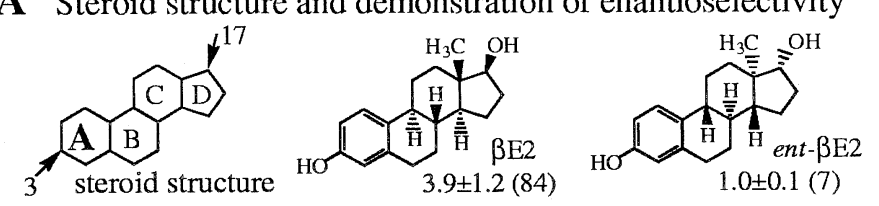

B Changes in the A-ring that eliminate potentiation

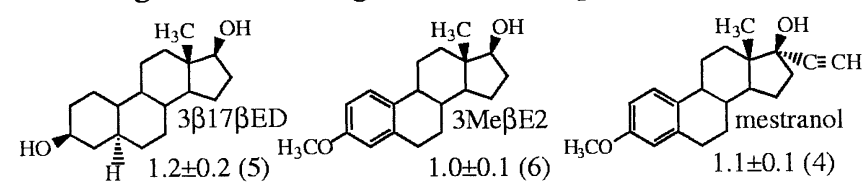

C Changes in the D-ring that eliminate potentiation
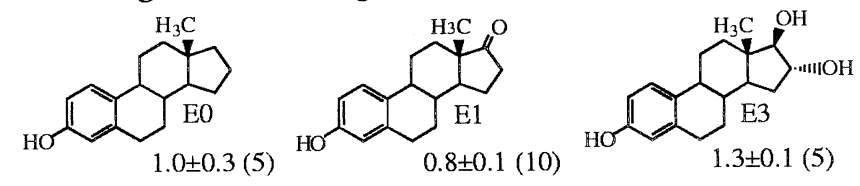

D Additional steroids that potentiate human $\alpha 4 \beta 2$ receptors
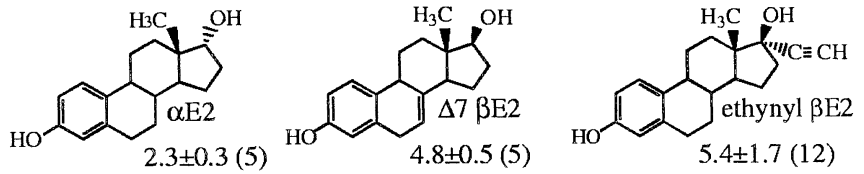

Figure 4. Steroids tested for their ability to potentiate the human $\alpha 4 \beta 2$ nicotinic receptor. The structures of the steroids are identified by the abbreviations in the text, and values indicate the ratio of the response to coapplication of $1 \mu \mathrm{M} \mathrm{ACh}$ and $15 \mu \mathrm{M}$ of the test compound to the response to $1 \mu \mathrm{M}$ ACh alone in the same oocyte $( \pm 1 \mathrm{SD}$, with the number of oocytes tested in parentheses). The stereochemistry at all optically active centers is shown for $\beta \mathrm{E} 2$ and ent- $\beta \mathrm{E} 2$; only partial stereochemistry for the other steroids is shown, but they are identical to that for $\beta \mathrm{E} 2$ at the additional centers. $A$, The structure in the top left corner shows the steroid ring backbone with the rings labeled $A-D$. The $A$ ring is in bold, and arrows point to carbons 3 and 17 to indicate the importance of these positions. Although $\beta \mathrm{E} 2$ potentiates responses, its mirror image (ent- $\beta \mathrm{E} 2)$ does not. $B$, Steroids containing a saturated $A$ ring $(3 \beta 17 \beta E D)$ or lacking a hydroxyl group at carbon $3(3 \mathrm{Me} \beta E 2$ and mestranol) do not potentiate. $C$, Absence of a hydroxyl group at carbon $17(E 0, E 1)$ or addition of a hydroxyl group at carbon $16(E 3)$ reduces potentiation. $D$, Potentiation occurs with an $\alpha$-hydroxyl at carbon $17(\alpha E 2)$, additional unsaturation in the $B$ ring $(\triangle 7 \beta E 2)$, or an ethynyl group added to carbon 17 (ethynyl $\beta E 2$ ).

whereas E1 and E3 are comparable with $\alpha \mathrm{E} 2$ in affinity and activity at human estrogen receptors (Kuiper et al., 1997; Wiese et al., 1997). In addition, two nonsteroidal agonists for the estrogen receptor inhibited responses from the $\alpha 4 \beta 2$ receptor: diethyl stilbestrol $(0.45 \pm 0.12 \mathrm{SD} ; n=4)$ and kampferol $(0.86 \pm 0.09 \mathrm{SD}$; $n=3)$. Accordingly, although there are similarities in the struc- 
ture-activity relationship for potentiation of the nicotinic receptor and activation of the estrogen receptor, there are clear differences that indicate structurally distinct estradiol binding sites for the $\alpha 4 \beta 2$ nicotinic receptor and the estrogen receptors. The differences in agonist selectivity combined with the speed of the response allow us to conclude that the potentiation of the $\alpha 4 \beta 2$ receptor is not mediated by steroids acting through an estrogen receptor.

\section{The C-terminal tail of the human $\alpha 4$ subunit is required for potentiation by estradiol}

The observation that the human $\alpha 4 \beta 2$ receptor is potentiated by $\beta \mathrm{E} 2$ and that the rat $\alpha 4 \beta 2$ receptor is not provided the opportunity to define the portions of the receptor that are required for potentiation. We first determined whether the species of origin for the $\alpha 4$ or the $\beta 2$ subunit was critical, by expressing all four subunit combinations. For this work, we used a standard test application of $1 \mu \mathrm{M}$ ACh plus $15 \mu \mathrm{M} \beta \mathrm{E} 2$ and measured the ratio of the response in the presence of steroid to the response in the absence of steroid. Both receptors containing the human $\alpha 4$ subunit were potentiated (human $\alpha 4$ plus human $\beta 2,1.58 \pm 0.36$ $\mathrm{SD} ; n=11$ ) (human $\alpha 4$ plus rat $\beta 2,2.08 \pm 0.34 \mathrm{SD} ; n=6$ ), whereas receptors containing the rat $\alpha 4$ subunit were not (rat $\alpha 4$ plus human $\beta 2,0.78 \pm 0.09 \mathrm{SD} ; n=3)($ rat $\alpha 4$ plus rat $\beta 2,0.77 \pm$ $0.04 \mathrm{SD} ; n=4)$. Accordingly, our attention focused on the differences between human and rat $\alpha 4$ subunits.

We produced three pairs of chimeric subunits between the human and rat $\alpha 4$ subunits, with joining points located in the $\mathrm{N}$-terminal extracellular region (in the cysteine-cysteine loop), at the $\mathrm{C}$-terminal end of the M3 membrane spanning region, and in the middle of the main cytoplasmic loop. In each case, potentiation mapped to the C-terminal portion of the human $\alpha 4$ subunit (data not shown). We noted that the rat and human $\alpha 4$ subunit differ at the extreme C-terminal region, in the extracellular "tail" that follows the M4 membrane spanning region. Accordingly, we constructed subunits in which only the last two (rat, PPWLA $\underline{\text { AC) }}$ ) or three (human, PPWLAGMI) residues were exchanged. This small region was sufficient to transfer potentiation to the rat $\alpha 4$ subunit and remove it from the human $\alpha 4$ subunit (Fig. $5 A$ ). It is interesting to note that there is no evidence that any other nonhomologous portions of the $\alpha 4$ subunits have a significant role in producing potentiation, because the potentiation observed was the same regardless of the nature of the subunit preceding the tail (Fig. $5 A$ ). We examined the possibility that the terminal cysteine of the rat $\alpha 4$ subunit acted to prevent potentiation, for example by disulfide bond formation (DiPaola et al., 1989). However, deletion of cysteine or replacement with isoleucine or serine did not confer potentiation (Fig. $5 B$ ).

To further determine that block and potentiation are separate, we also tested the ability of PROG to block responses from the subunits with exchanged C-terminal tails. As shown in Table 2, we found that the exchange had little or no effect on block, confirming that the sites involved in potentiation and block are distinct. None of the differences were significant $(p>0.2$ for all pairwise comparisons). It therefore appeared that the human $\alpha 4$ $\mathrm{C}$ terminus did not affect block, but instead contained a sequence of amino acids that conferred potentiation.

\section{Specific residues in the human $\alpha 4 \mathrm{C}$ terminus are required for potentiation}

Mutation of residues in the human $\alpha 4$ tail sequence revealed that the nature of the final four residues (AGMI) was critical, whereas

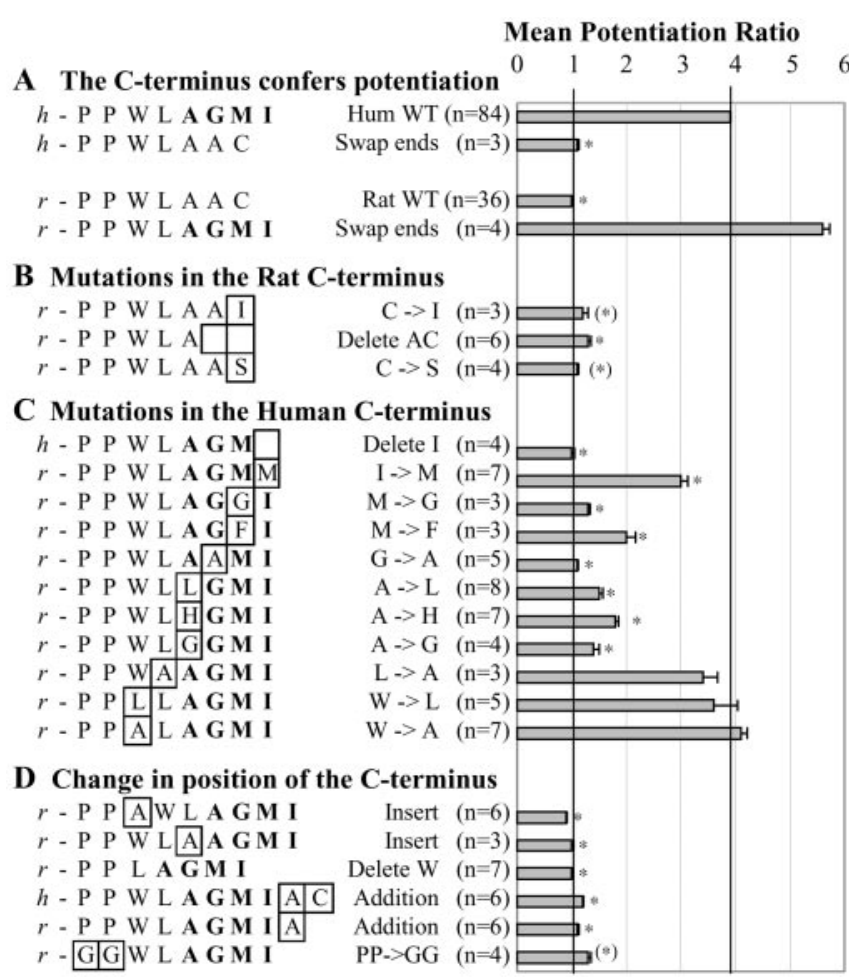

Figure 5. Mutations in the C-terminal tail of the $\alpha 4$ subunit affect potentiation by $\beta E 2$. Oocytes were injected with an $\alpha 4$ construct and wild-type $\beta 2$ subunit. The first column shows the $C$-terminal amino acid sequence for each construct with the first entry $(r$, rat; $h$, human) indicating the origin of the sequence before the $\mathrm{C}$ terminus of the subunit. The sequence follows the predicted end of the M4 membrane spanning region, with the proline pair $(P P)$ aligned vertically. The critical four residues are shown in bold, and the locations of mutations are boxed. The next column briefly describes each construct, followed by the $n$ value. The bar graph to the right shows the mean ratio of the response to $1 \mu \mathrm{M}$ ACh plus $15 \mu \mathrm{M}$ $\beta \mathrm{E} 2$ to the response to $1 \mu \mathrm{M} \mathrm{ACh}$ alone in the same oocyte. The vertical lines at 1 and 3.85 indicate the average response from rat (no potentiation) and human $\alpha 4 \beta 2$ receptors. Error bars indicate the SEM. *indicates a $p<$ 0.05 that the difference between the ratio for each construct and the ratio for human wild-type receptor, obtained from the same batch of oocytes (see Materials and Methods), arises by chance (evaluated using the $t$ test assuming unequal variances); (*) is the same as *, except data from these three constructs were compared with the pooled data from all human wild-type receptors because wild-type responses were not determined from the same batch of oocytes.

the preceding two residues (WL) were less important for potentiation by $\beta E 2$ (Fig. $5 C$ ). Deletion of the ultimate isoleucine removed potentiation, whereas substitution with methionine reduced it. Similarly, alterations of the methionine, glycine, or alanine reduced potentiation.

In contrast, mutation of leucine to alanine and mutation of tryptophan to leucine or alanine did not reduce $\beta \mathrm{E} 2$ potentiation (Fig. 5C). These observations indicate that these residues are unlikely to interact strongly with $\beta \mathrm{E} 2$.

Not only the nature but the position of the AGMI residues is critical. For convenience, we will speak as though the two prolines at the end of the M4 region define a fixed position with respect to the membrane and the rest of the receptor. Moving the AGMI sequence out from the prolines by inserting an alanine or moving it in toward the prolines by deleting the tryptophan removed potentiation (Fig. 5D). These observations demonstrate that the presence of AGMI as the terminal sequence, in and of itself, is not sufficient to confer potentiation. However, the relative posi- 


\begin{tabular}{|c|c|c|c|c|}
\hline & Human WT & Rat WT & $\begin{array}{l}\text { Human with Rat } \\
\text { CT }\end{array}$ & $\begin{array}{l}\text { Rat with Human } \\
\text { CT }\end{array}$ \\
\hline$\alpha 4 \mathrm{CT}$ sequence & $h$-PPWLAGMI & $r$-PPWLAAC & $h$-PPWLAAC & $r$-PPWLAGMI \\
\hline $1 \mu \mathrm{M}$ ACh plus $15 \mu \mathrm{M}$ PROG & $0.16 \pm 0.10(n=4)$ & $0.08 \pm 0.02(n=5)$ & $0.12 \pm 0.11(n=4)$ & $0.13 \pm 0.18(n=3)$ \\
\hline
\end{tabular}

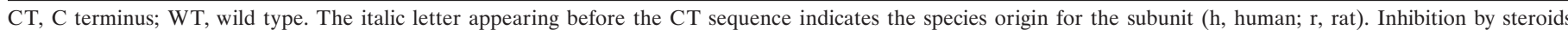

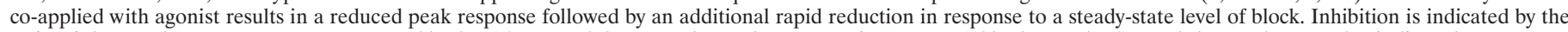
ratio of the steady-state response to $1 \mu \mathrm{M}$ ACh plus $15 \mu \mathrm{M}$ PROG versus the peak response from $1 \mu \mathrm{M}$ ACh alone. The SD and the $n$ value are also indicated.

tion of AGMI with respect to the prolines is not the only critical feature, because extension of the tail by adding one or two residues after the isoleucine also reduced or removed potentiation (Fig. $5 D$ ). Both prolines were mutated to glycine, with the thought that increased flexibility might result in a structure that retains potentiation. However, this mutation also reduced potentiation (Fig. $5 D$ ), perhaps because the rigid bend introduced by the prolines is required for correct positioning of the tail. These observations are consistent with the idea that the tail occupies a relatively confined volume and must be able to adopt a particular conformation to allow recognition of $\beta \mathrm{E} 2$. It is possible that reduced potentiation found with the relatively small changes of alanine to glycine or glycine to alanine (Fig. $5 C$ ) also reflects a tight binding pocket requiring a specific conformation.

\section{The $\mathbf{C}$-terminal tail sequence acts as a steroid binding site}

We think that the tail is most likely to be involved in recognition of the steroid. The data summarized in Figure 5 do not rule out the possibility that the AGMI sequence is required for conformational changes involved in transducing the binding of $\beta \mathrm{E} 2$ into the observed potentiation. However, an additional observation provides strong evidence that $\mathrm{C}$-terminal residues interact directly with the steroid. We found that ethynyl $\beta \mathrm{E} 2$ potentiates rat $\alpha 4 \beta 2$ receptors (Fig. 6), which is unique among the steroids we have tested (Paradiso et al., 2000). For the rat $\alpha 4 \beta 2$ receptor, this steroid has an $\mathrm{EC}_{50}$ value that is between 3 and $10 \mu \mathrm{M}$ (data not shown), and $15 \mu \mathrm{M}$ yields $\sim 75 \%$ of the potentiation seen with 30 $\mu \mathrm{M}$ (the highest concentration tested).

We reasoned that the unsaturated ethynyl moiety $(\mathrm{C} \equiv \mathrm{C})$ might interact with the aromatic group in the tryptophan side chain in the C-terminal tail. Accordingly, we mutated the tryptophan to leucine to remove the $\pi$ electrons while retaining the hydrophobic nature of the side chain. The mutation was made in both the human (WLAGMI to LLAGMI) and rat tail (WLAAC to LLAAC). We then compared the abilities of $\beta E 2$ and ethynyl $\beta E 2$ to potentiate receptors containing the constructs. As shown in Figure 6, receptors containing $\alpha 4$ subunits that had a tail with sequences of either WLAGMI or LLAGMI were potentiated by both $\beta E 2$ and ethynyl $\beta E 2$, as expected based on our previous results, because the AGMI sequence is present. In contrast, a tail sequence of WLAAC supported potentiation only by ethynyl $\beta E 2$ but not $\beta E 2$. Finally, LLAAC did not support potentiation by either steroid, consistent with it lacking both the tryptophan and the AGMI sequence.

The absence of steroid potentiation in the LLAAC construct could also be explained by an increase in steroid block. In fact, application of $\beta \mathrm{E} 2$ to receptors containing the $\mathrm{W}$ to $\mathrm{L}$ mutation produced a $26 \%$ reduction in the peak response (Fig. 6). To further address this, we tested the ability of progesterone to block the LLAAC construct and compared this with block of wild-type rat receptors. Progesterone was coapplied with ACh to match the

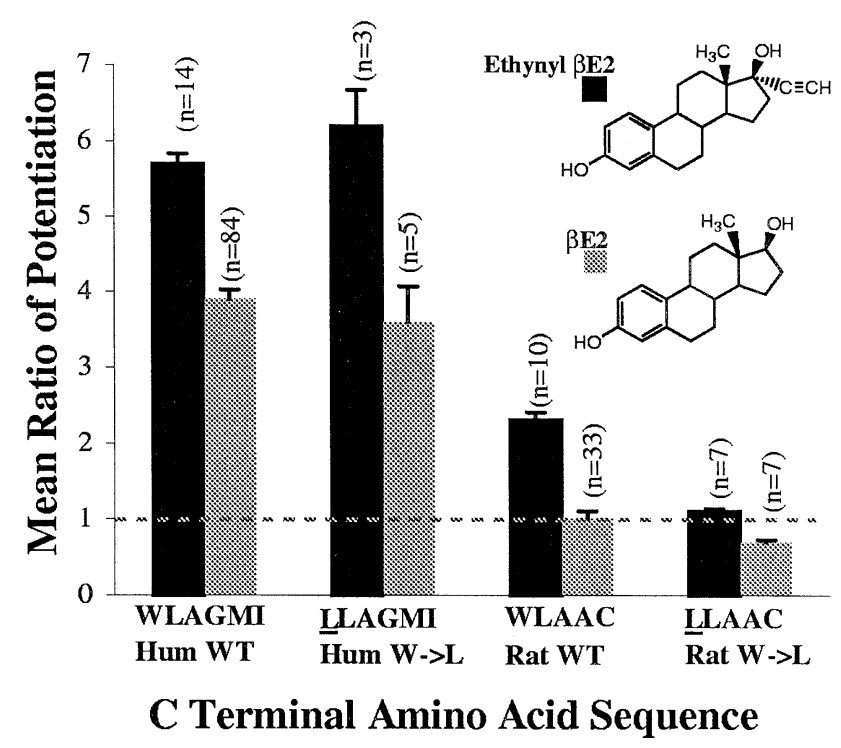

Figure 6. Mutations in the $\mathrm{C}$ terminus of the $\alpha 4$ subunit differentially affect the ability of steroids to potentiate responses to ACh. The horizontal axis indicates the sequence of the $\mathrm{C}$ terminus of the $\alpha 4$ subunit, injected with the wild-type $\beta 2$ subunit. The bars indicate the response to $1 \mu \mathrm{M}$ ACh and $15 \mu \mathrm{M}$ steroid ( $\beta \mathrm{E} 2$ or ethynyl $\beta \mathrm{E} 2$ ) compared with $1 \mu \mathrm{M}$ ACh alone. Error bars indicate the SEM, with the $n$ value indicated above each bar. The dotted line at the value of 1.0 indicates no potentiation.

protocol for application of potentiating steroids. At $3 \mu \mathrm{M}$, progesterone reduced the peak response of rat $\alpha 4 \beta 2$ receptors by $43 \%$ $( \pm 0.08 \mathrm{SD} ; n=6)$ and that of LLAAC-containing receptors by $45 \%( \pm 0.09 \mathrm{SD} ; n=4)$. At $15 \mu \mathrm{M}$, however, progesterone reduced the peak response of rat $\alpha 4 \beta 2$ receptors by $63 \%( \pm 0.04$ $\mathrm{SD} ; n=6)$ and that of LLAAC-containing receptors by $76 \%$ $( \pm 0.06 \mathrm{SD} ; n=4)$. Although there is a small increase in the ability of high concentrations of progesterone to block the LLAAC receptors, this small difference is not enough to account for the complete loss of potentiation by ethynyl estradiol.

These results from Figure 6 demonstrate that the AGMI sequence is not absolutely required for potentiation, because ethynyl $\beta E 2$ can potentiate a receptor with the WLAAC tail sequence. Similarly, the tryptophan residue (W) is not required for potentiation, because both $\beta \mathrm{E} 2$ and ethynyl $\beta \mathrm{E} 2$ can potentiate receptors with the sequence LLAGMI. Our interpretation of these results is that both $\beta \mathrm{E} 2$ and ethynyl $\beta \mathrm{E} 2$ interact with the AGMI sequence. However, the vinyl group of ethynyl $\beta \mathrm{E} 2$ can also interact with the tryptophan. Accordingly, to remove binding of ethynyl $\beta \mathrm{E} 2$ it was necessary to remove both sites of interaction from the protein.

On the basis of these data, it appears that the steroid rings and/or the ethynyl group bind to the $\alpha 4 \mathrm{C}$ terminus, leaving the two hydroxyl groups of the steroid free to hydrogen bond to amino acids elsewhere in the protein. The data indicate that the 
$\mathrm{C}$ terminus acts as a binding domain, although additional regions of the receptor are likely necessary for the conformational changes required for potentiation.

\section{DISCUSSION}

\section{The binding site involved in steroid potentiation differs from that for inhibition}

$17 \beta$-Estradiol and some structurally similar steroids potentiate responses of human $\alpha 4 \beta 2$ receptors, whereas many other steroids inhibit responses. Our work indicates that steroids must bind to different regions of the receptor to have these two divergent actions. In pharmacological experiments, progesterone produces the same level of block for control responses and for responses potentiated by 3 or $15 \mu \mathrm{M} \beta \mathrm{E} 2$, indicating that PROG and $\beta \mathrm{E} 2$ must bind to nonoverlapping regions of the receptor to produce block or potentiation. In addition, mutations of the $\alpha 4$ subunit have shown that the regions of the receptor that are important for potentiation do not affect block. Hence, although block and potentiation both involve binding of steroids, the C-terminal amino acids that are essential for potentiation are not necessary for block. Previous studies of GABA (Zaman et al., 1992) and NMDA (Park-Chung et al., 1997) receptors have also found that inhibition and potentiation by steroids are independent processes.

\section{Steroid recognition by the $\mathbf{C}$ terminus of the $\alpha \mathbf{4}$ subunit}

Our observations were made using a physiological assay, and potentiation reflects both steroid binding and the ensuing conformational changes that result in potentiation. Our data indicate that the $\mathrm{C}$ terminus of the $\alpha 4$ subunit is involved in steroid recognition and that the specific residues have less of an effect on the subsequent conformational changes. The most compelling evidence for this conclusion is the finding that the tryptophan in the $\mathrm{C}$ terminus has a specific role in recognizing the $17 \alpha$ ethynyl moiety $(\mathrm{C} \equiv \mathrm{C})$ in ethynyl $\beta \mathrm{E} 2$, probably through a $\pi-\pi$ interaction between the benzene ring of the tryptophan and the ethynyl group. We think that ethynyl $\beta \mathrm{E} 2$ interacts with two portions of the $\mathrm{C}$ terminus, both the tryptophan and the terminal tetrapeptide AGMI, because the presence of either allows potentiation by ethynyl $\beta \mathrm{E} 2$. $17 \beta$-Estradiol, in contrast, interacts only with the AGMI peptide.

Because the two oxygen atoms in the $\beta \mathrm{E} 2$ molecule are only $\sim 1$ nm apart (Anstead et al., 1997), it is possible that the C-terminal tail adopts a sufficiently extended conformation that allows it to provide much of the binding site for $\beta \mathrm{E} 2$. It is also possible that the $\alpha 4 \mathrm{C}$-terminal carboxylate group forms a hydrogen bond to one of the hydroxyls of the steroid. However, the C-terminal tail cannot provide the entire binding site because it does not contain residues that specifically interact with both hydroxyl groups in $\beta E 2$. In the estrogen receptor, a glutamate and a histidine interact with the 3- and 17-hydroxyls, respectively (Tanenbaum et al., 1998). It is thought that the interaction with the hydroxyl groups is critical for activation of estrogen receptors. In the $\alpha 4 \beta 2$ nicotinic receptor, the two hydroxyl groups appear to be essential for potentiation (Fig. 4), and it is possible that the hydroxyl groups are important in translating binding into potentiation.

All of the residues that we have identified as interacting with $\beta \mathrm{E} 2$ are hydrophobic. In the estrogen receptor, there are 15 hydrophobic interactions involved in stabilizing the association between $\beta E 2$ and the receptor (Tanenbaum et al., 1998), and the free energy of binding is actually derived primarily from hydrophobic interactions (Anstead et al., 1997). The lower apparent affinity of the nicotinic receptor would suggest that there are fewer hydrophobic interactions between the receptor and $\beta \mathrm{E} 2$. However, the two receptors are similar in the sense that both apparently recognize steroids containing a rigid diol with a hydrophobic and appropriately shaped spacer region.

\section{Estradiol is synthesized in the CNS}

The high nanomolar to low micromolar levels of $\beta E 2$ required for potentiation represent a high concentration relative to the concentration necessary to activate the $\alpha 1$ and $\beta 1(0.1-1 \mathrm{~nm})$ or $\beta 2$ (10-100 nM) estrogen receptors (Petersen et al., 1998; Hanstein et al., 1999). However, the nongenomic actions of $\beta \mathrm{E} 2$ generally require nanomolar to micromolar concentrations (Moosmann and Behl, 1999; Valverde et al., 1999), and it has been proposed that local production by aromatase can result in high local concentrations of $\beta E 2$ (Balthazart and Ball, 1998; Stoffel-Wagner et al., 1999). It is also possible that the relevant concentration of $\beta \mathrm{E} 2$ is the concentration found in the synaptic membrane, which would be increased by partitioning into the membrane. Therefore, the possibility exists that the local $\beta \mathrm{E} 2$ concentration might be significantly higher than the bulk CSF levels at sites at which the aromatase enzyme is located. Currently, the methods used to measure steroid levels are not capable of measuring local concentrations of steroid.

\section{Steroids and ligand-gated ion channels}

Transmitter-gated ion channels have been shown to be one target responsible for the rapid action of neuroactive steroids. Steroids can potentiate or inhibit the responses of several different receptors to transmitters, and in some cases a given steroid may potentiate one type of receptor while inhibiting another. Two well studied examples of steroid modulation of transmitter-gated ion channels are the potentiation of $\mathrm{GABA}_{\mathrm{A}}$ receptors (cf. Paul and Purdy, 1992) and the inhibition of NMDA receptors (ParkChung et al., 1997). Although many studies have been made of the structural features of the steroid that enhance or reduce activity on a transmitter-gated channel, there has been no success to date in identifying the regions of any receptor that interact with steroids (Rick et al., 1998; Blanton et al., 1999). Studies of chimeric subunits have suggested that the ability of the anesthetic steroid alphaxalone to potentiate the $\mathrm{GABA}_{\mathrm{A}}$ receptor requires regions of the receptor located between the $\mathrm{N}$ terminus and the middle of the second transmembrane spanning region (Rick et al., 1998). In that study, however, it was not possible to distinguish between the parts of the receptor involved in steroid recognition and those regions required for conformational changes. The steroid promegestone inhibits the muscle-type nicotinic receptor found in Torpedo electric organ, and photolabeling experiments have shown that it interacts with residues in the M4 membrane spanning helix (Blanton et al., 1999). However, promegestone is an inhibitory steroid, and our data indicate that inhibition and potentiation of the $\alpha 4 \beta 2$ nicotinic receptor by steroids does not involve an overlapping binding site.

We show a direct interaction between the human $\alpha 4 \beta 2$ neuronal nicotinic receptor and $\beta$-estradiol by locating a specific region of the human $\alpha 4 \beta 2$ receptor that is necessary for potentiation of responses by estradiol steroids. This work represents the first example of a specific region required for steroidal effects on an ion channel, reveals an important role for the $\mathrm{C}$ terminus of ligand-gated ion channels, and suggests an additional mechanism for some of the nongenomic effects of estrogen. 


\section{REFERENCES}

Anand R, Lindstrom J (1990) Nucleotide sequence of the human nicotinic acetylcholine receptor $\beta 2$ subunit gene. Nucleic Acids Res 18:4272.

Anstead GM, Carlson KE, Katzenellenbogen JA (1997) The estradiol pharmacophore: ligand structure-estrogen receptor binding affinity relationships and a model for the receptor binding site. Steroids 62:268-303.

Balthazart J, Ball GF (1998) New insights into the regulation and function of brain estrogen synthase (aromatase). Trends Neurosci 21:243-249.

Bertrand D, Valera S, Bertrand S, Ballivet M, Rungger D (1991) Steroids inhibit nicotinic acetylcholine receptors. NeuroReport 2:277-280.

Blanton MP, Xie Y, Dangott LJ, Cohen JB (1999) The steroid promegestone is a noncompetitive antagonist of the Torpedo nicotinic acetylcholine receptor that interacts with the lipid-protein interface. Mol Pharmacol 55:269-278.

Briggs CA, McKenna DG, Piattonikaplan M (1995) Human $\alpha 7$ nicotinic acetylcholine receptor responses to novel ligands. Neuropharmacology 34:583-590.

Buisson B, Bertrand S, Bertrand D (1998) Inhibition and potentiation of human nicotinic receptors by sex hormones. Soc Neurosci Abstr 24:530.19.

Coggan JS, Paysan J, Conroy WG, Berg DK (1997) Direct recording of nicotinic responses in presynaptic nerve terminals. $J$ Neurosci 17:5798-5806.

Colman A (1984) Expression of exogenous DNA in Xenopus oocytes. In: Transcription and translation: a practical approach (Hames BD, Higgins SJ, eds), pp 49-69. Washington, DC: Oxford.

Deneris ES, Connolly J, Boulter J, Wada E, Wada K, Swanson LW, Patrick J, Heinemann S (1988) Primary structure and expression of $\beta 2$ : a novel subunit of neuronal nicotinic acetylcholine receptors. Neuron 1:45-54.

DiPaola M, Czajkowski C, Karlin A (1989) The sidedness of the COOH terminus of the acetylcholine receptor $\delta$ subunit. $\mathrm{J}$ Biol Chem 264:15457-15463.

Flores CM, Rogers SW, Pabreza LA, Wolfe BB, Kellar KJ (1992) A subtype of nicotinic cholinergic receptor in rat brain is composed of $\alpha 4$ and $\beta 2$ subunits and is up-regulated by chronic nicotine treatment. Mol Pharmacol 41:31-37.

Gray R, Rajan AS, Radcliffe KA, Yakehiro M, Dani JA (1996) Hippocampal synaptic transmission enhanced by low concentrations of nicotine. Nature 383:713-716.

Hanstein B, Liu H, Yancisin MC, Brown M (1999) Functional analysis of a novel estrogen receptor- $\beta$ isoform. Mol Endocrinol 13:129-137.

Kuiper GG, Carlsson B, Grandien K, Enmark E, Haggblad J, Nilsson S, Gustafsson JA (1997) Comparison of the ligand binding specificity and transcript tissue distribution of estrogen receptors $\alpha$ and $\beta$. Endocrinology 138:863-870.

Kuryatov A, Gerzanich V, Nelson M, Olale F, Lindstrom J (1997) Mutation causing autosomal dominant nocturnal frontal lobe epilepsy alters $\mathrm{Ca}^{2+}$ permeability, conductance, and gating of human $\alpha 4 \beta 2$ nicotinic acetylcholine receptors. J Neurosci 17:9035-9047.

Lindstrom J (1997) Nicotinic acetylcholine receptors in health and disease. Mol Neurobiol 15:193-222.

Marubio LM, Arroyo-Jimenez MD, Cordero-Erausquin M, Lena C, Le Novere N, d'Exaerde AD, Huchet M, Damaj MI, Changeux JP (1999) Reduced antinociception in mice lacking neuronal nicotinic receptor subunits. Nature 398:805-810.

McEwen BS, Alves SE (1999) Estrogen actions in the central nervous system. Endocr Rev 20:279-307.
McGehee DS, Heath MJS, Gelber S, Devay P, Role LW (1995) Nicotine enhancement of fast excitatory synaptic transmission in CNS by presynaptic receptors. Science 269:1692-1696.

Moosmann B, Behl C (1999) The antioxidant neuroprotective effects of estrogens and phenolic compounds are independent from their estrogenic properties. Proc Natl Acad Sci USA 96:8867-8872.

Paradiso K, Sabey K, Evers AS, Zorumski CF, Covey DF, Steinbach JH (2000) Steroid inhibition of rat neuronal nicotinic $\alpha 4 \beta 2$ receptors expressed in HEK 293 cells. Mol Pharmacol 58:341-351.

Park-Chung M, Wu FS, Purdy RH, Malayev AA, Gibbs TT, Farb DH (1997) Distinct sites for inverse modulation of $N$-methyl-D-aspartate receptors by sulfated steroids. Mol Pharmacol 52:1113-1123.

Paterson D, Nordberg A (2000) Neuronal nicotinic receptors in the human brain. Prog Neurobiol 61:75-111.

Paul SM, Purdy RH (1992) Neuroactive steroids. FASEB J 6:2311-2322.

Petersen DN, Tkalcevic GT, Koza-Taylor PH, Turi TG, Brown TA (1998) Identification of estrogen receptor $\beta 2$, a functional variant of estrogen receptor $\beta$ expressed in normal rat tissues. Endocrinology 139:1082-1092.

Rick CE, Ye Q, Finn SE, Harrison NL (1998) Neurosteroids act on the GABA-A receptor at sites on the N-terminal side of the middle of TM2. NeuroReport 9:379-383.

Robel P, Baulieu EE (1995) Neurosteroids: biosynthesis and function. Crit Rev Neurobiol 9:383-394.

Rupprecht R, Holsboer F (1999) Neuroactive steroids: mechanisms of action and neuropsychopharmacological perspectives. Trends Neurosci 22:410-416.

Sabey K, Paradiso K, Zhang J, Steinbach JH (1999) Ligand binding and activation of rat nicotinic $\alpha 4 \beta 2$ receptors stably expressed in HEK293 cells. Mol Pharmacol 55:58-66.

Stoffel-Wagner B, Watzka M, Schramm J, Bidlingmaier F, Klingmuller D (1999) Expression of CYP19 (aromatase) mRNA in different areas of the human brain. J Steroid Biochem Mol Biol 70:237-241.

Sugaya K, Giacobini E, Chiappinelli VA (1990) Nicotinic acetylcholine receptor subtypes in human frontal cortex: changes in Alzheimer's disease. J Neurosci Res 27:349-359.

Tanenbaum DM, Wang Y, Williams SP, Sigler PB (1998) Crystallographic comparison of the estrogen and progesterone receptor's ligand binding domains. Proc Natl Acad Sci USA 95:5998-6003.

Valera S, Ballivet M, Bertrand D (1992) Progesterone modulates a neuronal nicotinic acetylcholine receptor. Proc Natl Acad Sci USA 89:9949-9953.

Valverde MA, Rojas P, Amigo J, Cosmelli D, Orio P, Bahamonde MI Mann GE, Vergara C, Latorre R (1999) Acute activation of Maxi-K channels (hSlo) by estradiol binding to the $\beta$ subunit. Science 285:1929-1931.

Wevers A, Monteggia L, Nowacki S, Bloch W, Schutz U, Lindstrom J, Pereira EF, Eisenberg H, Giacobini E, de Vos RA, Steur EN, Maelicke A, Albuquerque EX, Schroder H (1999) Expression of nicotinic acetylcholine receptor subunits in the cerebral cortex in Alzheimer's disease: histotopographical correlation with amyloid plaques and hyperphosphorylated- $\tau$ protein. Eur J Neurosci 11:2551-2565.

Wiese TE, Polin LA, Palomino E, Brooks SC (1997) Induction of the estrogen specific mitogenic response of $\mathrm{MCF}-7$ cells by selected analogues of estradiol-17ß: a 3D QSAR study. J Med Chem 40:3659-3669.

Wonnacott S (1997) Presynaptic nicotinic ACh receptors. Trends Neurosci 20:92-98.

Zaman SH, Shingai R, Harvey RJ, Darlison MG, Barnard EA (1992) Effects of subunit types of the recombinant $\mathrm{GABA}_{\mathrm{A}}$ receptor on the response to a neurosteroid. Eur J Pharmacol 225:321-330. 